\title{
Suicidal Ideation and Suicide Attempts in a Nationwide Sample of Operational Norwegian Ambulance Personnel
}

\author{
Tom Sterud ${ }^{1}$, Erlend Hem ${ }^{1}$, Bjørn $\mathrm{LaU}^{2}$ and Øivind Ekeberg ${ }^{1}$ \\ ${ }^{1}$ Department of Behavioural Sciences in Medicine, Institute of Basic Medical Sciences, Faculty of Medicine, \\ University of Oslo and ${ }^{2}$ National Institute of Occupational Health, Norway
}

\begin{abstract}
Suicidal Ideation and Suicide Attempts in a Nationwide Sample of Operational Norwegian Ambulance Personnel: Tom Sterud, et al. Department of Behavioural Sciences in Medicine, Institute of Basic Medical Sciences, Faculty of Medicine, University of Oslo, Norway-This is the first paper on suicidal ideation and attempts among ambulance personnel. This study aimed to investigate levels of suicidal ideation and suicide attempts among ambulance personnel, and to identify important correlates and the factors to which ambulance personnel attribute their serious suicidal ideation. A comprehensive nationwide questionnaire survey of 1,180 operational ambulance personnel was conducted. Measurements included: Paykel's Suicidal Feelings in the General Population questionnaire, the Hospital Anxiety and Depression scale, the Subjective Health Complaints Questionnaire, the Maslach Burnout Inventory, the Job Satisfaction Scale, the Basic Character Inventory, and the Rosenberg Self-Esteem Scale. Lifetime prevalence ranged from $28 \%$ for feelings that life was not worth living to $10.4 \%$ for seriously considered suicide and $3.1 \%$ for a suicide attempt. Serious suicidal ideation was independently associated with job-related emotional exhaustion (feelings of being overextended and depleted of resources) (OR 1.5, 95\% $\mathrm{Cl} 1.1-2.0)$ and bullying at work (OR 1.7, 95\% Cl 1.02-2.7), younger age, not married/cohabitant, depression symptoms, low selfesteem and the personality trait reality weakness. In general, suicidal thoughts were hardly attributable to working conditions, since only $1.8 \%$ of ambulance personnel attributed suicidal ideation to work problems alone. In conclusion, ambulance personnel reported a moderate level of suicidal ideation and suicide attempts. Although serious suicidal ideation was rarely
\end{abstract}

Received Feb 21, 2008; Accepted Jun 3, 2008

Published online in J-STAGE Jul 25, 2008

Correspondence to: T. Sterud, Department of Behavioral Sciences in Medicine, PO Box 1111 Blindern, NO-0317 Oslo, Norway

(e-mail: tom.sterud@medisin.uio.no) attributed to working conditions in general, this study suggests that job-related factors like emotional exhaustion and bullying may be of importance.

(J Occup Health 2008; 50: 406-414)

Key words: Suicide, Help-seeking, Stress, Psychological, Personality, Emergency Medical Services, Emergency Medical Technicians

High suicide rates have been reported in some health care occupations (e.g., physicians, dentists and nurses) compared with other occupational groups ${ }^{1,2)}$. However, few occupations have been the subject of empirical research on attempted suicide. This is the first study to address the prevalence of suicidal ideation and suicide attempts among ambulance personnel ${ }^{3)}$.

Elevated rates of suicidal ideation and suicide attempts in a particular occupational group may result from a complex interaction between job-related factors such as work stress, aspects of the occupational culture, the presence of mental disorders and self-selection by vulnerable individuals ${ }^{4}$. Within ambulance services, a high level of suicidal ideation and suicide attempts may be engendered by factors such as the potential for psychologically traumatic work. Ambulance personnel are exposed to dangerous situations and emotionally challenging relationships when dealing with clients, their relatives and bystanders, which might put them at risk of high levels of psychological distress. Moreover, as shown in a recent systematic review, a consistently high level of psychological distress has been reported among ambulance personnel, manifested as symptoms of posttraumatic stress, anxiety, depression and burnout. Ambulance personnel are also shown to report more somatic health problems than the general population, such as musculoskeletal injuries and low back pain ${ }^{3)}$. All of these factors are reported in the literature to contribute to higher levels of suicidal ideation and suicide attempts ${ }^{5-7)}$. Thus, a high prevalence of suicidal ideation and suicide attempts among ambulance personnel may be expected. 
However, there are no available national statistics on suicide rates among ambulance personnel to support this claim.

A poor social climate constitutes another important stressor adversely affecting employees' health. The last decade has witnessed an increase in studies focusing on systematic interpersonal harassment and bullying ${ }^{8,9)}$. Bullying at work has been reported to be most frequent in stressful work environments ${ }^{10)}$ and may therefore be an important indicator of a poor social climate within ambulance services. Targets of bullying often lack social support from coworkers and leaders and report high levels of psychosomatic symptoms, psychological distress or depressive symptoms ${ }^{8,11}$. Moreover, bullying has been reported as a risk factor for suicide attempts in studies of adolescents $^{12}$. However, bullying as a possible risk factor for suicidal ideation and suicide attempts has to our knowledge not been studied in an occupational setting.

Individual characteristics of employees may be as important as the workplace in terms of the creation of suicidal ideation and suicide attempts. Neuroticism has most frequently been reported as contributing to suicidal behaviour $^{13,14)}$. Moreover, the importance of the personality trait reality weakness as a risk factor for suicidal ideation has been reported in other human service populations in Norway, specifically police and physicians ${ }^{15,16)}$. Some studies have also indicated that high levels of extroversion and self-esteem may protect against suicidal ideation ${ }^{17,18)}$. In most population-based studies, the demographic correlates for higher levels of suicidal ideation have been identified as younger age and disrupted or single marital status $^{19-21)}$. In most general population studies, suicidal ideation is equally common in men and women, or slightly more common in women ${ }^{20-22)}$. However, being female in a male-dominated working environment such as ambulance services may be a risk factor for higher levels of job stress and suicidal ideation among female ambulance employees.

Most research on health personnel has focused on suicide itself. In the present study, the focus was on suicidal ideation and suicide attempts, with special emphasis on serious suicidal ideation, which, in the present study, was defined as a planned suicide attempt. The rationale for focusing on serious suicidal ideation is that a planned attempt is both one of the strongest risk factors for completed suicide and an important indicator of extreme emotional distress ${ }^{20)}$. Moreover, planned attempts may be targeted for preventive efforts. Despite this, little is known about the help-seeking behaviours of persons with serious suicidal ideation in the general population ${ }^{23)}$. Against this background, we conducted a study to address the following questions in a nationwide sample of operational ambulance personnel.

1a. Are there high levels of suicidal ideation and suicide attempts among ambulance personnel?

1b. To what extent do employees with serious suicidal ideation seek help?

2. What are the important correlates of serious suicidal ideation among ambulance personnel?

3. To which factors do ambulance personnel attribute their serious suicidal ideation?

\section{Materials and Methods}

\section{Sample}

Ambulance services in Norway are organized into 19 main ambulance regions that are responsible for ensuring adequate ambulance services. Some hospitals have their own integrated ambulance departments but in several regions, ambulance services are organized as independent units separate from hospitals. In several rural locations ambulance services cover small populations. The educational background of ambulance personnel in Norway ranges from workers with no formal ambulance training to those with formal ambulance education at high school or college level. Additionally, some ambulance personnel are nurses or auxiliary nurses.

In April 2005, questionnaires were sent to the chiefs of all 19 ambulance regions in Norway. They had agreed to distribute the questionnaires to all ambulance personnel in the ambulance stations within their regions. This procedure was chosen because there was no central national register of all employed ambulance personnel in Norway available at that time. Two written reminders were distributed through the ambulance chiefs, and two major worker union organizations encouraged their members to answer the questionnaire through notices on their home pages and in their membership journals. Respondents gave their consent to participate in the study by returning the questionnaire. The Regional Committee for Medical Research Ethics, Southern Norway, reviewed and advised the project. A total of 3,200 questionnaires were sent out. Based on reports from four of the ambulance chiefs, 64 ambulance personnel were excluded because they were no longer employed in the service, resulting in 3,136 questionnaires being distributed to personnel. A total of 1,286 persons returned questionnaires, giving a response rate of $41 \%$. Responses were obtained from all ambulance regions. The response rates in the different regions ranged from $31 \%$ to $59 \%$, median $41.5 \%$, with the exception of one region with the lowest response rate of $10 \%$. Overall, $53.4 \%$ of the respondents reported to work in rural settings (defined as serving a population with fewer than 20,000 inhabitants), and $46.6 \%$ reported to work in an urban setting (defined as serving a population with more than 20,000 inhabitants. Overall, the data show that responses to our questionnaire are rather representative of ambulance personnel on a national level.

Logistic regression analyses were used to compare levels of suicidal ideation and suicide attempts and to test the assumption that the bivariate associations were 
similar in those who responded in the main round and those who responded after one or two reminders. We found no significant differences in mean scores and no significant interactions between the bivariate associations and time of response.

Participants in this study included officers, middle managers, and managers who reported doing ambulance work more than $50 \%$ of their work time $(n=1,180)$. The term operational ambulance personnel is used to describe these respondents. The majority of respondents $(76.8 \%)$ were male. The age of the participants ranged from 18 to $66 \mathrm{yr}$, with a mean (SD) age of $36.8(9.3) \mathrm{yr}$; the mean age was 37.6 (9.0) for males and 33.8 (9.6) for females $(p<0.001)$. Missing responses to questions regarding gender $(n=6)$ or age $(n=31)$ were excluded from the analyses. In all, $85.4 \%$ of the total sample reported to have shift arrangements. The average weekly working hours were $39.5 \mathrm{~h}(\mathrm{SD}=14.5)$ per week. Neither the length of the working week nor the type of working hours (shift work or regular day work) were significantly related to suicidal ideation. These variables were therefore omitted from the analyses.

\section{Instruments}

1) Dependent variables

The prevalence of suicidal ideation and suicide attempts was assessed by a modified questionnaire, originally introduced by Paykel et al. ${ }^{24)}$. Paykel's Suicidal Feelings in the General Population questionnaire contains five questions.

1. Have you ever felt that life was not worth living?

2. Have you ever wished you were dead (for instance, that you could get to sleep and not wake up)?

3. Have you ever thought of taking your life, even if you would not really do it?

4. Have you ever reached the point where you seriously considered taking your life and even made plans for how you would go about doing it?

5. Have you ever made an attempt to take your life?

The responses were dichotomized into never (0) and any frequency (1), according to Paykel's original work.

Questions 4 and 5 contained an additional sub-question, "To what extent do you think the following factors influenced you to consider taking your life?" with the following response categories: personal problems, family problems, social problems, problems connected with the ambulance profession, and other problems (not specified). The responses could be indicated as: not at all, a little, somewhat, quite a lot, and very much.

In the multivariate analyses, any occurrence of serious suicidal ideation (item 4) was used as the dependent variable, reported as lifetime prevalence. The rationale for focusing upon lifetime prevalence was to obtain sufficient statistical strength to identify statistically significant correlates and to allow comparisons with other studies of human service populations in Norway (physicians and police) ${ }^{16,25)}$. However, because of recall bias, the use of lifetime prevalence as a dependent variable may suffer from methodological limitations. Hence, in additional analyses, serious suicidal ideation in the last year was used as a dependent variable in order to be able to compare lifetime correlates to last-year correlates of serious suicidal ideation. In order to obtain a sufficiently large number of cases, we included those with a positive response on last-year suicidal thoughts (item 3) and/or last-year serious suicidal ideation (item 4).

2) Independent variables

The Hospital Anxiety and Depression Scale ${ }^{26}$ includes 14 questions divided into two subscales: an anxiety subscale (seven items; $\alpha=0.8$ ) and a depression subscale (seven items; $\alpha=0.7$ ). Each item is scored from 0 to 3 during the last 14 days, allowing each dimension a range of scores between 0 (low) and 21 (high).

Somatic complaints were assessed by a 10 -item version of the Subjective Health Complaint questionnaire ${ }^{27)}$. The items are scored on a four-point rating scale ranging from no complaints ( 0 ) to serious complaints (3) during the last 30 days. The score is computed as the mean of valid responses $(\alpha=0.72)$.

Personality was measured by the Basic Character Inventory (BCI), which is based on an original questionnaire constructed by Lazare, Klerman, \& Armor $^{28)}$ and modified by Torgersen ${ }^{29)}$. BCI is based on the 'big three' personality dimensions: neuroticism $(\alpha=0.74)$, extroversion $(\alpha=0.72)$ and control $(\alpha=0.66)$, with an additional fourth dimension, reality weakness $(\alpha=0.67)$, which measures chronic illusions, paranoid traits, and problems with identity-insecurity and relations-traits that are associated with severe personality disorders ${ }^{29)}$. It is not a measure of psychosis, but of possible tendencies of not facing reality such as day dreaming or wishful thinking. Each dimension is based on nine questions with a dichotomous response ( $0=$ does not apply, $1=$ applies), allowing each dimension a range of scores between 0 (low) and 9 (high). Reality weakness was applied as a categorical variable with three categories (Table 1).

Self-esteem was measured with a four-item version of the Norwegian translation of the Rosenberg Self-Esteem Scale ${ }^{30,31)}$. All items are scored on a scale from 1 (highest level) to 4 (lowest level). The score was computed as the mean of valid responses $(\alpha=0.71)$.

The Job Satisfaction Scale (JSS) consists of ten questions examining various aspects of working conditions and stressors: responsibility, variation, collaboration, salary, working hours, etc. $(\alpha=0.85)^{32)}$. All items were scored on a scale from 1 (extremely satisfied) to 7 (extremely dissatisfied). The score was computed as the mean of valid responses.

Burnout was measured with a 22-item version of the 
Table 1. Description of the independent variables

\begin{tabular}{|c|c|c|c|c|}
\hline & Range & Mean & SD & $\mathrm{N}$ \\
\hline \multirow[t]{2}{*}{ Gender* } & Women & $23.2 \%$ & & 1,175 \\
\hline & Men & $76.8 \%$ & & \\
\hline \multirow[t]{2}{*}{ Civil status* } & Married & $75.0 \%$ & & 1,110 \\
\hline & Not married & $25.0 \%$ & & \\
\hline Age & $(18-66)$ & 36.8 & 9.3 & 1,149 \\
\hline Neuroticism & $(0-9)$ & 2.7 & 2.2 & 1,173 \\
\hline Extroversion & $(0-9)$ & 5.6 & 2.3 & 1,175 \\
\hline Control & $(0-9)$ & 3.7 & 2.1 & 1,175 \\
\hline Reality Weakness* & 0 & $41.1 \%$ & & 1,173 \\
\hline (Respondents with a reality weakness & $<1.2$ & $39.5 \%$ & & \\
\hline Score of 0 was used a reference group) & $>2$ & $19.4 \%$ & & \\
\hline Low self-esteem & $(1-4)$ & 1.7 & 0.5 & 1,166 \\
\hline Depression symptoms & $(0-21)$ & 2.6 & 2.7 & 1,165 \\
\hline Anxiety symptoms & $(0-21)$ & 3.6 & 2.9 & 1,165 \\
\hline Somatic complaints & $(0-3)$ & 0.4 & 0.3 & 1,162 \\
\hline Emotional exhaustion & $(1-4)$ & 1.9 & 0.6 & 1,160 \\
\hline Depersonalization & $(1-4)$ & 1.7 & 0.6 & 1,164 \\
\hline Personal Accomplishment & $(1-4)$ & 3.5 & 0.4 & 1,164 \\
\hline Job dissatisfaction & $(1-7)$ & 3.1 & 1.0 & 1,167 \\
\hline \multirow[t]{2}{*}{ Bullying at work* } & Never & 72.8 & & 1,175 \\
\hline & Any & 27.2 & & \\
\hline
\end{tabular}

Categorical variables are marked with an asterisk $(*)$.

Maslach Burnout Inventory-Human Services Survey ${ }^{33)}$. The inventory contains questions regarding the three factors that define burnout: emotional exhaustion (feelings of being overextended and depleted of resources; nine items; $\alpha=0.86$ ), depersonalization (a cynical and distant attitude toward one's work and the people one works with; four items; $\alpha=0.68$ ), and a reduced feeling of personal accomplishment (the tendency to evaluate one's achievements at work negatively; eight items; $\alpha=0.69$ ). The items are scored on a five-point scale ranging from 1 to 5 during the last 14 days. The score was computed as the mean of valid responses.

Bullying at work was measured with a single item: Have you, during the last year, been exposed to harassment or bullying from colleagues or superiors? The answer categories were: never, seldom, sometimes or often. Before the statistical analyses, the responses were dichotomized into never (0) and any frequency (1). Total prevalence was $27.2 \%$ with no significant gender differences (women: 29.3\%; men: 26.6\%; $p=0.39$ ). There were no significant differences in level of suicidal ideation among personnel who reported bullying seldom as compared to sometimes or often $(10 \%$ and $2.3 \%$, respectively).

With the sociodemographic data, marital status was dichotomized into married/cohabitant (reference) and single/divorced/separated/widow(er). Age was used as a continuous variable with a one-unit change representing $10 \mathrm{yr}$. Gender was coded with female as a reference category.

Mental help-seeking was measured with two items: "Have you ever had mental health problems? and [if Yes] Did you seek/receive help for them?" Response alternatives were: 1 . Have had no mental health problems of importance; 2. Have not sought help, although I have needed it; 3 . Yes, have consulted a general practitioner; 4. Yes, have consulted a psychologist/psychiatrist; 5. Yes, have been admitted to a hospital psychiatric department.

\section{Statistics}

Means and frequencies were used to describe the variables in the present study, and the $\chi^{2}$ test was used to test for gender differences in suicidal ideation. Simultaneous effects of the included independent variables were estimated by logistic regression analyses. The assumption of linearity in the logit held approximately for all independent health variables (except for the personality variable reality weakness, which was split into three equal groups). Hence, all independent variables were treated as continuous variables and standardized in the present analyses, with the exception of gender, marital status and reality weakness. 
Table 2. Prevalence of suicidal ideation and suicide attempts in Norwegian ambulance personnel

\begin{tabular}{|c|c|c|c|c|c|c|c|c|c|}
\hline \multirow{4}{*}{$\begin{array}{l}\text { Total respondents } \\
\text { Felt life was not worth living }\end{array}$} & \multirow{2}{*}{\multicolumn{3}{|c|}{$\begin{array}{c}\text { Total respondents } \\
\text { All (women/men) }\end{array}$}} & \multicolumn{3}{|c|}{ Life-time (\%) (95\%CI) } & \multicolumn{3}{|c|}{ Last year (\%) (95\%CI) } \\
\hline & & & & \multirow{2}{*}{$\begin{array}{c}\text { All } \\
28.0\end{array}$} & \multirow{2}{*}{$\begin{array}{c}\text { Women } \\
32.4\end{array}$} & \multirow{2}{*}{$\begin{array}{l}\text { Men } \\
26.7\end{array}$} & \multirow{2}{*}{$\begin{array}{c}\text { All } \\
8.3\end{array}$} & \multirow{3}{*}{$\begin{array}{c}\text { Women } \\
7.3 \\
4.3-10.5\end{array}$} & \multirow{2}{*}{$\begin{array}{l}\text { Men } \\
8.6\end{array}$} \\
\hline & 1,168 & 272 & 896 & & & & & & \\
\hline & & & & $25.4-30.6$ & $26.8-37.9$ & $23.8-29.6$ & $6.7-9.9$ & & $6.8-10.4$ \\
\hline \multirow[t]{2}{*}{ Wished you were dead } & 1,158 & 268 & 890 & 20.7 & 26.1 & $19.1 *$ & 6.2 & 7.5 & 5.8 \\
\hline & & & & $18.4-23.1$ & $20.9-31.4$ & $16.5-21.7$ & $4.8-7.6$ & $4.3-10.6$ & $4.3-7.4$ \\
\hline \multirow[t]{2}{*}{ Thought of taking your life } & 1,158 & 269 & 889 & 22.8 & 24.9 & 22.2 & 5.7 & 6.3 & 5.5 \\
\hline & & & & $20.4-25.2$ & $19.7-30.1$ & $19.4-24.9$ & $4.4-7.0$ & $3.4-9.2$ & $4.6-7.0$ \\
\hline \multirow{2}{*}{$\begin{array}{l}\text { Seriously considered } \\
\text { taking your life }\end{array}$} & 1,158 & 270 & 888 & 10.4 & 11.1 & 10.1 & 1.9 & 1.9 & 1.9 \\
\hline & & & & $8.6-12.1$ & $7.4-14.9$ & $8.2-12.1$ & $1.1-2.7$ & $0.3-3.5$ & $1.0-2.8$ \\
\hline \multirow[t]{2}{*}{ Attempted suicide } & 1,142 & 266 & 876 & 3.1 & 4.5 & 2.6 & 0.4 & 0.8 & 0.3 \\
\hline & & & & $2.1-4.1$ & $2.0-7.0$ & $1.6-3.7$ & $0.1-0.8$ & $0-1.8$ & $0.0-0.7$ \\
\hline
\end{tabular}

${ }^{*} p<0.05$

\section{Results}

As can be seen from Table 2, 28\% of the ambulance personnel had on one or more occasions felt that life was not worth living, and $22.8 \%$ reported lifetime suicidal ideation. Additionally, $10.4 \%$ had seriously considered suicide, and 35 persons $(3.1 \%)$ had attempted suicide. The last-year prevalence was $8.3 \%, 5.7 \%, 1.9 \%$ and $0.4 \%$, respectively. In general, there were no gender differences in reported suicidal ideation and suicide attempts, except for higher lifetime prevalence of 'wished you were dead' among women (26.1 vs. $19.1, p<0.05)$.

Among those reporting lifetime serious suicidal ideation, $51 \%$ had not sought professional help; $40 \%$ did not recognize that they had had mental problems and $11 \%$ reported not seeking help although needing it. Fortynine percent reported seeking help for mental problems. Overall, $13 \%$ had visited a general practitioner only, 28\% had contacted a psychologist and $8 \%$ had been admitted to a hospital psychiatric department.

As shown in Table 3 , in the adjusted model, being unmarried and of younger age were associated with serious suicidal ideation. Among the mental health variables, depression symptoms were significantly associated with serious suicidal ideation. Anxiety symptoms and somatic complaints, although bivariately associated, were not significant in the adjusted model. Among the personality variables, reality weakness and low self-esteem were significantly associated with serious suicidal ideation. Neuroticism, although bivariately associated with serious suicidal ideation, was no longer significant in the adjusted model. Furthermore, among the job-related variables, higher levels of emotional exhaustion and bullying at work were associated with serious suicidal ideation. Two-way interaction analyses with gender and all other independent variables were tested. None of these interactions were significant (not shown).

In general, rather similar adjusted estimates were found for lifetime serious suicidal ideation correlates compared with last-year serious suicidal ideation correlates (Pearson's $r=0.6, p<0.001$ ): Not married OR, 1.8 vs. 1.5; Age OR 0.7 vs. 0.8; Depression symptoms OR, 1.3 vs. 1.1; Low self-esteem OR, 1.4 vs.1.7; Emotional exhaustion OR, 1.5 vs. 1.4; and Bullying at work OR, 1.7 vs.1.6. However, reality weakness was more strongly related to last-year serious suicidal ideation. It should be noted, however, that age, marital status, and bullying at work were not statistically significant in the last-year analyses. Moreover, in contrast to the lifetime serious suicidal ideation analyses, anxiety symptoms but not depression symptoms were related to last-year serious suicidal ideation.

As can be seen from Table 4, serious suicidal ideation was most typically attributed to personal and family problems among both women and men. There were no significant gender differences with the exception of the significantly larger proportion of men who attributed serious suicidal ideation to 'other problems'. Serious suicidal ideation was least frequently attributed to work related problems, with $4 \%$ of the women and $11 \%$ of the men reporting work problems as an important factor, whereas $1.8 \%$ reported work problems as the only factor of importance. A similar attribution profile was given by those reporting last-year serious suicidal ideation.

\section{Discussion}

Rates of lifetime prevalence of serious suicidal ideation $(10.4 \%)$ and attempted suicide $(3.1 \%)$ among ambulance personnel were similar to, and statistically not significantly different from, those reported among Norwegian physicians ${ }^{25}$, but they were significantly higher than the prevalence rates reported among Norwegian police $(6.4 \% \text { and } 0.7 \% \text {, respectively })^{16)}$. 
Table 3. Regression of (serious) suicidal ideation among Norwegian ambulance personnel

\begin{tabular}{|c|c|c|c|c|c|c|c|c|c|c|c|c|}
\hline & \multicolumn{5}{|c|}{$\begin{array}{l}\text { Serious suicidal ideation } \\
\quad \text { (life-time })^{1}(\mathrm{n}=1,022)\end{array}$} & \multicolumn{7}{|c|}{$\begin{array}{l}\text { Suicidal thoughts and serious suicidal } \\
\text { ideation (last year })^{2}(n=963)\end{array}$} \\
\hline & \multicolumn{2}{|c|}{ Unadjusted } & & \multicolumn{2}{|c|}{ Adjusted } & & \multicolumn{2}{|c|}{ Unadjusted } & & \multicolumn{3}{|c|}{ Adjusted } \\
\hline & Odds & $95 \% \mathrm{CI}$ & & Odds & $95 \% \mathrm{CI}$ & & Odds & $95 \% \mathrm{CI}$ & & Odds & $95 \% \mathrm{CI}$ & \\
\hline Female & 0.9 & $(0.6-1.4)$ & $\mathrm{ns}$ & 1.4 & $(0.8-2.5)$ & $\mathrm{ns}$ & 0.9 & $(0.6-1.5)$ & $\mathrm{ns}$ & 1.2 & $(0.6-2.4)$ & ns \\
\hline Not married & 2.3 & $(1.5-3.4)$ & $* * *$ & 1.7 & $(1.1-2.8)$ & $*$ & 2.9 & $(1.9-4.3)$ & $* * *$ & 2.1 & $(1.2-3.8)$ & $*$ \\
\hline Age & 0.7 & $(0.6-0.9)$ & $* *$ & 0.6 & $(0.5-0.9)$ & $* *$ & 0.7 & $(0.6-0.9)$ & $* *$ & 0.6 & $(0.5-0.9)$ & $*$ \\
\hline Reality weakness & 3.5 & $(1.9-6.4)$ & $* * *$ & 2.6 & $(1.3-5.1)$ & $* *$ & 3.8 & $(1.9-7.3)$ & $* * *$ & 2 & $(0.9-4.8)$ & ns \\
\hline & 10.5 & $(5.8-19.0)$ & $* * *$ & 4 & $(1.8-8.7)$ & $* *$ & 27.6 & $(14.4-53.1)$ & $* * *$ & 5 & $(2.0-12.8)$ & $* *$ \\
\hline$(\mathrm{ref}=0)$ & & & & & & & & & & & & \\
\hline Neuroticism* & 1.7 & $(1.4-2.0)$ & $* * *$ & 0.8 & $(0.6-1.1)$ & $\mathrm{ns}$ & 2.9 & $(2.4-3.6)$ & $* * *$ & 1.3 & $(1.0-1.8)$ & ns \\
\hline Self-esteem* & 1.9 & $(1.6-2.3)$ & $* * *$ & 1.4 & $(1.1-1.9)$ & $*$ & 3.7 & $(2.8-4.8)$ & $* * *$ & 1.6 & $(1.1-2.3)$ & $* *$ \\
\hline Depression symptoms* & 1.9 & $(1.6-2.2)$ & $* * *$ & 1.3 & $(1.0-1.7)$ & $*$ & 2.7 & $(2.2-3.2)$ & $* * *$ & 1.3 & $(1.0-1.8)$ & ns \\
\hline Anxiety symptoms* & 2 & $(1.7-2.3)$ & $* * *$ & 1.2 & $(0.9-1.6)$ & $\mathrm{ns}$ & 3.3 & $(2.7-4.2)$ & $* * *$ & 1.4 & $(1.0-1.9)$ & ns \\
\hline Somatic complaints* & 1.5 & $(1.3-2.7)$ & $* * *$ & 1.2 & $(0.9-1.5)$ & $\mathrm{ns}$ & 1.6 & $(1.3-1.9)$ & $* * *$ & 1.2 & $(0.9-1.7)$ & ns \\
\hline Emotional exhaustion* & 2 & $(1.7-2.4)$ & $* * *$ & 1.5 & $(1.1-2.0)$ & $*$ & 2.8 & $(2.2-3.5)$ & $* * *$ & 1.4 & $(1.0-2.1)$ & ns \\
\hline Depersonalisation* & 1.4 & $(1.2-1.7)$ & $* * *$ & 0.8 & $(0.6-1.0)$ & $\mathrm{ns}$ & 1.9 & $(1.6-2.3)$ & $* * *$ & 1 & $(0.8-1.4)$ & ns \\
\hline Personal accomplishment* & 1 & $(0.8-1.2)$ & $\mathrm{ns}$ & 1.3 & $(1.0-1.7)$ & $\mathrm{ns}$ & 0.8 & $(0.6-0.9)$ & $* *$ & 1 & $(0.7-1.3)$ & ns \\
\hline Job dissatisfaction* & 1.3 & $(1.1-1.6)$ & $* *$ & 0.8 & $(0.6-1.0)$ & $\mathrm{ns}$ & 1.7 & $(1.4-2.0)$ & $* * *$ & 1 & $(0.7-1.4)$ & ns \\
\hline Bullying at work & 2.8 & $(1.9-4.2)$ & $* * *$ & 1.6 & $(1.0-2.7)$ & $*$ & 3.4 & $(2.3-5.0)$ & $* * *$ & 1.5 & $(0.8-2.8)$ & $\mathrm{ns}$ \\
\hline Constant & & & & 0.04 & & & & & & 0.05 & & \\
\hline
\end{tabular}

${ }^{*} p<0.05 ; * * p<0.01$; ${ }^{+}$These scores were transformed into $\mathrm{z}$-scores; ns: not significant. ${ }^{1}$ Serious suicidal ideation=question 4 in Paykel's questionnaire. ${ }^{2}$ Suicidal thoughts and serious suicidal ideation=question 3 and 4 in Paykel's questionnaire.

Table 4. Attributed impacting factors on lifetime serious suicidal ideation

\begin{tabular}{lccc}
\hline & & \multicolumn{2}{c}{$\begin{array}{c}\text { Percentage who answered } \\
\text { Quite a bit or very much }\end{array}$} \\
\cline { 2 - 4 } & N (women / men) & Women & Men \\
\hline Personal problems & $114(27 / 87)$ & 67 & 62 \\
Family problems & $118(30 / 88)$ & 70 & 51 \\
Social problems & $110(26 / 84)$ & 15 & 27 \\
Work problems & $111(27 / 84)$ & 4 & 11 \\
Other problems & $109(25 / 84)$ & 8 & $38^{* *}$ \\
\hline
\end{tabular}

$* p<0.05 ; * *<<0.01$. Comparison between scores for Quite a bit + Very much vs. not at all + a little + somewhat.

However, suicidal thoughts were much less frequent among ambulance personnel compared with physicians, and similar to levels among Norwegian police (last-year prevalence rates: $5.7 \%$ vs. $11.1 \%$ [physicians] and $7.5 \%$ [police]).

Comparisons with general population studies of suicidal ideation are difficult, as prevalence rates have been reported to vary widely, partly due to different settings, populations, definitions of suicidal ideation and applied measures, and the use of a retrospective framework $^{34)}$. Population-based studies of serious suicidal ideation and suicide attempts, as measured with the
Paykel questionnaire, report lifetime prevalence for suicidal plans of $4.4-13 \%$ and for suicide attempts of $2.7-4.4 \%{ }^{35,36}$. Concerning suicidal thoughts, in a recent cross-national population based study, last-year prevalence rates were reported to range between $2.3 \%$ and $14.6 \%$, with Norway at an intermediate level of $7.4 \%{ }^{22)}$, whereas last-year prevalence of suicidal thoughts, as measured by the Paykel measure, has been reported at $8.6 \%$ in Sweden ${ }^{36)}$. Thus, ambulance personnel reported moderate levels of suicidal thoughts, serious suicidal ideation and suicide attempts, with levels similar to those reported among other human service professions in 
Norway and within the range of what is reported in general population studies.

Only a few general population studies have been published regarding help-seeking among persons with serious suicidal ideation ${ }^{23)}$. The present finding that about $50 \%$ reported seeking help for mental problems accords with the level of help-seeking among respondents reporting serious suicidal ideation in general population studies $^{19,37)}$. Among help-seekers, the largest proportion had visited a psychologist or a psychiatrist. Thus, the present data do not support the assumption that ambulance personnel with serious suicidal ideation may be particularly opposed to seeking help for mental health problems $^{38)}$.

Two novel findings from this study were that jobrelated emotional exhaustion and bullying at work were independently associated with higher levels of serious suicidal ideation. These findings imply that serious suicidal ideation within ambulance services may be directly related to the working environment and cannot be explained only by self-selection of vulnerable persons or the level of mental health problems. These findings somewhat contradict the finding that serious suicidal ideation was least frequently attributed to work problems by both genders. Only $1.8 \%$ of ambulance personnel attributed suicidal ideation to work problems alone. Both males and females attributed serious suicidal ideation much more frequently to personal and family problems, which is similar to what was reported among Norwegian police and physicians ${ }^{16,25)}$. A possible interpretation is that although suicidal thoughts were rarely attributed to working conditions, workplace characteristics are most likely of importance both as an independent factor related to higher levels of suicidal ideation and possibly also as a factor that may interact with personal problems and family problems among persons who develop serious suicidal ideation.

In accordance with what is reported in most general population studies, depression symptoms were significantly positively related to serious suicidal ideation. However, although bivariately associated, neither anxiety symptoms nor somatic complaints were significantly associated with serious suicidal ideation in the adjusted model. This partly contradicts what was reported among Norwegian police and physicians, that somatic complaints were independently associated with serious suicidal ideation $^{16,25)}$. In the present analyses, this was partly explained by the moderately high intercorrelations between somatic complaints, anxiety and depression symptoms and emotional exhaustion (Pearson's $r$ ranging between $0.35-0.57$ ).

The personality dimension reality weakness was identified as the dispositional factor most strongly associated with suicidal ideation, which accords with what has been observed among both Norwegian police and physicians ${ }^{16,39)}$. Moreover, low self-esteem was independently associated with serious suicidal ideation. The results for the role of neuroticism in understanding suicide were mixed in the current study. No single variable could explain why the positive relationship between neuroticism and suicidal ideation was no longer significant in the adjusted model. The effect of neuroticism was shown to be partly mediated by higher levels of depression and anxiety symptoms among those employees with higher levels of neuroticism, but there was also a substantial intercorrelation between neuroticism and the personality traits found to be independently associated with suicidal ideation in the present study. A common characteristic in people who report low self-esteem and high neuroticism scores is that they are continually preoccupied with their inadequacies. They are likely to show depressive affect as a consequence of contemplating their shortcomings because they find so little that is tolerable within themselves and therefore may also be prone to suicidal ideation.

Younger age and living alone were associated with higher levels of serious suicidal ideation, which accords with findings from a large number of general population studies. On the other hand, there was no significant effect for gender. Other studies have reported higher levels of serious suicidal ideation among female physicians ${ }^{25}$, whereas no gender difference was reported among police ${ }^{16)}$. Thus, the effect of being female in a maledominated working environment such as the ambulance services shows mixed findings.

\section{Strengths and limitations}

This is the first study to address the level of suicidal ideation and suicide attempts among ambulance personnel. Further, this study was nationwide and applied several validated international instruments. However, some limitations of this study should be considered. First, this study was cross-sectional, which means that no conclusions can be drawn with regard to the direction of the reported relationships. There was only a moderate response rate, which may call into question the representativeness of the data. Fear of factors such as lack of anonymity and professional consequences may have led to underreporting and possibly also a lower response rate among ambulance personnel with a higher rate of suicidal ideation. On the other hand, however, there were no significant differences in mean scores and no significant interactions between the bivariate associations and time of response (in the ambulance personnel sample). As late responders may resemble the nonrespondents ${ }^{40)}$, the lack of representativeness may not be a severe problem. Moreover, as similar approaches were used among Norwegian physicians and police, comparisons with these groups are most likely valid. The use of lifetime prevalence as a dependent variable may 
suffer from methodological limitations because of recall bias. However, given the similarities in estimated adjusted odds ratios for lifetime serious suicidal ideation and last-year suicidal ideation, this bias is not likely to be severe.

\section{Conclusions}

Contrary to common beliefs, the prevalence of serious suicidal ideation and suicide attempts among ambulance personnel was at a moderate level, and comparable to those among other human service occupations in Norway. Among employees reporting suicidal ideation, the prevalence of help-seeking was higher than expected but even so, $51 \%$ reported that they had not sought help for mental health problems. Although serious suicidal ideation was rarely attributed to working conditions, this study suggests that workplace characteristics are most likely to be of importance. Job-related emotional exhaustion and bullying at work were independently related to serious suicidal ideation when the data were adjusted for depression and anxiety symptoms, and the personality traits independently associated with serious suicidal ideation, reality weakness and low self-esteem. Thus, as people spend a lot of time in the workplace, this may be a useful arena for targeting people who not only are struggling with job-related problems but possibly also social and personal problems.

Acknowledgments: The study was funded by The Eastern Norway Regional Health Authority and The Laerdal Foundation for Acute Medicine. The authors thank Arne Henriksen and Stein T. Moen (SOSCON) for practical assistance during the planning of this study.

\section{References}

1) Agerbo E, Gunnell D, Bonde JP, Bo MP and Nordentoft M: Suicide and occupation: the impact of socioeconomic, demographic and psychiatric differences. Psychol Med 1-10 (2007)

2) Hem E, Haldorsen T, Aasland OG, Tyssen R, Vaglum $\mathrm{P}$ and Ekeberg O: Suicide rates according to education with a particular focus on physicians in Norway 1960 2000. Psychol Med 35, 873-880 (2005)

3) Sterud T, Ekeberg O and Hem E: Health status in the ambulance services: a systematic review. BMC Health Serv Res 6, 82 (2006)

4) Boxer PA, Burnett C and Swanson N: Suicide and occupation: a review of the literature. J Occup Environ Med 37, 442-452 (1995)

5) Thoresen S and Mehlum L: Suicide in peacekeepers: risk factors for suicide versus accidental death. Suicide Life Threat Behav 36, 432-442 (2006)

6) Nakao M, Yamanaka G and Kuboki T: Suicidal ideation and somatic symptoms of patients with mind/body distress in a Japanese psychosomatic clinic. Suicide Life Threat Behav 32, 80-90 (2002)

7) Gili-Planas M, Roca-Bennasar M, Ferrer-Perez V and
Bernardo-Arroyo M: Suicidal ideation, psychiatric disorder, and medical illness in a community epidemiological study. Suicide Life Threat Behav 31, 207-213 (2001)

8) Einarsen S: Harassment and bullying at work: a review of the Scandinavian approach. Aggression and Violent Behavior 5, 379-401 (2000)

9) Rayner $\mathrm{C}$ and Hoel $\mathrm{H}$ : A summary review of literature relating to workplace bullying. J Comm Appl Soc Psychol 7, 181-191 (1997)

10) Hansen AM, Hogh A, Persson R, Karlson B, Garde $\mathrm{AH}$ and Orbaek P: Bullying at work, health outcomes, and physiological stress response. J Psychosom Res 60, 63-72 (2006)

11) Niedhammer I, David S and Degioanni S: Association between workplace bullying and depressive symptoms in the French working population. J Psychosom Res 61, 251-259 (2006)

12) Kaltiala-Heino R, Rimpela M, Marttunen M, Rimpela A and Rantanen P: Bullying, depression, and suicidal ideation in Finnish adolescents: school survey. Br Med J 319, 348-351 (1999)

13) Brezo J, Paris J and Turecki G: Personality traits as correlates of suicidal ideation, suicide attempts, and suicide completions: a systematic review. Acta Psychiatr Scand 113, 180-206 (2006)

14) Kerby DS: CART analysis with unit-weighted regression to predict suicidal ideation from Big Five traits. Pers Individ Differ 35, 249-261 (2003)

15) Tyssen R, Hem E, Vaglum P, Gronvold NT and Ekeberg $\mathrm{O}$ : The process of suicidal planning among medical doctors: predictors in a longitudinal Norwegian sample. J Affec Disord 80, 191-198 (2004)

16) Berg AM, Hem E, Lau B, Loeb $M$ and Ekeberg O: Suicidal ideation and attempts in Norwegian police. Suicide Life Threat Behav 33, 302-312 (2003)

17) Vilhjalmsson R, Kristjansdottir G and Sveinbjarnardottir E: Factors associated with suicide ideation in adults. Soc Psychiatry Psychiatr Epidemiol 33, 97-103 (1998)

18) Deman AF, Leduc CP and Labrechegauthier L: Correlates of suicide ideation in French-Canadian adults and adolescents - a comparison. J Clin Psychol 48, 811-816 (1992)

19) Hintikka J, Pesonen T, Saarinen P, Tanskanen A, Lehtonen J and Viinamaki H: Suicidal ideation in the Finnish general population. A 12-month follow-up study. Soc Psychiat Psychiatr Epidemiol 36, 590-594 (2001)

20) Kessler RC, Borges G and Walters EE: Prevalence of and risk factors for lifetime suicide attempts in the National Comorbidity Survey. Arch Gen Psychiatry 56, 617-626 (1999)

21) Weissman MM, Bland RC, Canino GJ, Greenwald S, Hwu HG, Joyce PR, Karam EG, Lee CK, Lellouch J, Lepine JP, Newman SC, Rubio-Stipec M, Wells JE, Wickramaratne PJ, Wittchen HU and Yeh EK: Prevalence of suicide ideation and suicide attempts in nine countries. Psychol Med 29, 9-17 (1999)

22) Casey PR, Dunn G, Kelly BD, Birkbeck G, Dalgard 
OS, Lehtinen V, Britta S, Ayuso-Mateos JL and Dowrick C: Factors associated with suicidal ideation in the general population: five-centre analysis from the ODIN study. Br J Psychiatry 189, 410-415 (2006)

23) Rancans E, Lapins J, Salander RE and Jacobsson L: Self-reported suicidal and help seeking behaviours in the general population in Latvia. Soc Psychiatry Psychiatr Epidemiol 38, 18-26 (2003)

24) Paykel ES, Myers JK, Lindenthal JJ and Tanner J: Suicidal feelings in the general population: a prevalence study. Br J Psychiatry 124, 460-469 (1974)

25) Hem E, Gronvold NT, Aasland OG and Ekeberg O: The prevalence of suicidal ideation and suicidal attempts among Norwegian physicians. Results from a cross-sectional survey of a nationwide sample. European Psychiatry 15, 183-189 (2000)

26) Zigmond AS and Snaith RP: The hospital anxiety and depression scale. Acta Psychiatr Scand 67, 361-370 (1983)

27) Ursin H, Endresen IM and Ursin G: Psychological factors and self-reports of muscle pain. Eur J Appl Physiol 57, 282-290 (1988)

28) Lazare A, Klerman GL and Armor DJ: Oral, obsessive, and hysterical personality patterns. An investigation of psychoanalytic concepts by means of factor analysis. Arch Gen Psychiatry 14, 624-630 (1966)

29) Torgersen S: Hereditary-environmental differentiation of general neurotic, obsessive, and impulsive hysterical personality traits. Acta Genet Med Gemellol (Roma) 29, 193-207 (1980)

30) Tambs K: Moderate effects of hearing loss on mental health and subjective well-being: results from the NordTrondelag Hearing Loss Study. Psychosom Med 66, 776-782 (2004)
31) Rosenberg M. Society and the adolescent self-image. Princeton, NJ: Princeton University Press, 1965.

32) Warr P, Cook J and Wall T: Scales for the measurement of some work attitudes and aspects of psychological well-being. J Occup Psychol 52, 129-148 (1979)

33) Maslach C, Schaufeli WB and Leiter MP: Job burnout. Annu Rev Psychol 52, 397-422 (2001)

34) Burless C and De Leo D: Methodological issues in community surveys of suicide ideators and attempters. Crisis 22, 109-124 (2001)

35) De Leo D, Cerin E, Spathonis K and Burgis S: Lifetime risk of suicide ideation and attempts in an Australian community: prevalence, suicidal process, and helpseeking behaviour. J Affect Disord 86, 215-224 (2005)

36) Renberg ES: Self-reported life-weariness, deathwishes, suicidal ideation, suicidal plans and suicide attempts in general population surveys in the north of Sweden 1986 and 1996. Soc Psychiatry Psychiatr Epidemiol 36, 429-436 (2001)

37) Kjoller M and Helweg-Larsen M: Suicidal ideation and suicide attempts among adult Danes. Scand J Public Health 28, 54-61 (2000)

38) Alexander DA and Klein S: Ambulance personnel and critical incidents: impact of accident and emergency work on mental health and emotional well-being. Br J Psychiatry 178, 76-81 (2001)

39) Tyssen R, Hem E, Vaglum P, Gronvold NT and Ekeberg $\mathrm{O}$ : The process of suicidal planning among medical doctors: predictors in a longitudinal Norwegian sample. J Affec Disord 80, 191-198 (2004)

40) Bakke P: Postal survey on airborne occupational exposure and respiratory disorders in Norway: causes and consequences of non-response. J Epidemiol Comm Health 44, 316-320 (1990) 